\title{
AS REDES GEOGRÁFICAS NA ANÁLISE DA PRODUÇÃO DE MEL EM SERGIPE
}

\author{
Maria do Socorro Ferreira da Silva ${ }^{1}$ \\ Edimilson Gomes da Silva ${ }^{2}$ \\ Rosemeri Melo e Souza ${ }^{3}$
}

\section{Resumo}

A apicultura é uma atividade que auxilia na conservação da biodiversidade e gera fonte de renda para os apicultores. Esse trabalho visa analisar a produção de mel em Sergipe a partir das redes geográficas. A pesquisa foi realizada através de levantamento bibliográfico; entrevistas com representantes da Federação dos Apicultores de Sergipe, com Associações de Apicultores e apicultores; e, pesquisa de campo nos apiários e territórios com potencial fitogeográfico. A configuração espacial das redes geográficas em Sergipe é composta pelas redes de produção; técnica-científica, informacional e financeira; e, de comercialização as quais ultrapassam os limites territoriais sergipanos alcançando a Bahia. As evidências apontam a necessidade de estratégias para melhorar o funcionamento das redes, promovendo a articulação entre seus nós de modo que não exclua os pequenos produtores.

Palavras-chave: Redes Geográficas; potencial fitogeográfico; produção de mel.

\section{NETWORKS IN GEOGRAPHICAL ANALYSIS OF THE HONEY PRODUCTION IN SERGIPE}

\begin{abstract}
Beekeeping is an activity that helps in the conservation of biodiversity and generate a source of income for beekeepers. This work aims to analyze the production of honey in Sergipe from geographical networks. The survey was conducted through literature; interviews with representatives of the Federation of Beekeepers of Sergipe, with Beekeepers Associations and beekeepers; and field research in apiaries and territories with phytogeographical potent. The spatial configuration of geographical networks in Sergipe consists of the production networks; technical-scientific, informational and financial; and marketing which exceed sergipanos boundaries reaching Bahia. The evidence suggests the need for strategies to improve the functioning of networks, promoting communication between its nodes so that does not exclude small producers.
\end{abstract}

Keywords: Geographic Networks; potential fitogeográfico; honey production.

\footnotetext{
${ }^{1}$ Doutora em Geografia, Prof ${ }^{a}$ Adjunta do Departamento de Geografia da Universidade Federal do Sergipe e Pesquisadora do GEOPLAN/UFS/CNPq. Email: ms.ferreira.s@ hotmail.com

${ }^{2}$ Doutor em Geografia pelo Programa de Pós-Graduação em Geografia (NPGEO) da Universidade Federal de Sergipe, e Pesquisador do GEOPLAN/UFS/CNPq. Email: dimil10@ hotmail.com

${ }^{3}$ Pós-doutora em Biogeografia e Prof ${ }^{a}$ Associada da Universidade Federal de Sergipe dos Cursos de Graduação e Pós-Graduação em Geografia/NPGEO/UFS e do Programa de Pós-Graduação em Desenvolvimento e Meio Ambiente (PRODEMA). Líder do GEOPLAN/UFS/CNPq, e Bolsista de Produtividade em Pesquisa do CNPq. Email: rome@ufs.br
} 


\section{LAS REDES GEOGRÁFICAS EN EL ANÁLISIS DE LA PRODUCCIÓN DE MIEL EN SERGIPE}

\section{Resumen}

La apicultura es una actividad que ayuda a la conservación de la biodiversidad y generar una fuente de ingresos para los apicultores. Este trabajo tiene como objetivo analizar la producción de miel en Sergipe de redes geográficas. La encuesta fue realizada a través de la literatura; entrevistas con representantes de la Federación de Apicultores de Sergipe, con los apicultores y asociaciones de apicultores; y la investigación de campo en las colmenas y territorios fitogeográfico potencial. La configuración espacial de las redes geográficas en Sergipe consta de las redes de producción; -Científico técnico, informativo y financiero; y comercialización, que superan los límites sergipanos alcance Bahía. La evidencia sugiere la necesidad de estrategias para mejorar el funcionamiento de las redes, la promoción de la comunicación entre sus nodos para que no excluye a los pequeños productores.

Palabras clave: Redes geográficas; fitogeográfico potencial; la producción de miel.

\section{INTRODUÇÃO}

No desenvolvimento contemporâneo da sociedade humana é impossível imaginar um determinado seguimento organizacional que não esteja ordenada em forma de rede, principalmente o espaço. Como ressalta Moreira (2007) quanto enfatiza que a partir da década de 1970 já não se pode mais ignorar a relação em rede, a qual se desponta como uma nova forma de organização geográfica da sociedade, articulando os diferentes lugares, moldando e estabelecendo as conexões que dão suporte às relações avançadas da produção e do mercado. Para o autor essa nova forma de organização vai modificando a forma e o conteúdo dos espaços.

Nessa perspectiva, as redes geográficas são definidas como "um conjunto de localizações geográficas interconectadas" entre si "por certo número de ligações", que pode ser constituído tanto por uma sede de cooperativa de produtores rurais e as fazendas a elas associadas, como por ligações (i)materiais que conectam a sede de uma empresa, seu centro de pesquisa e desenvolvimento, suas fábricas, depósitos e filiais de venda, assim, como podem ser constituídos por agências de um banco e seus fluxos de informação que circulam entre elas (CORRÊA, 1999, p. 107).

As redes são definidas como um "conjunto de nós interconectados, sendo nó o ponto no qual uma curva se entrecorta". Sendo assim, as redes são estruturas abertas capazes de aumentar de forma ilimitada integrando novos nós conectados dentro da mesma rede, ou seja, compartilhando os mesmos sinais de comunicação (CASTELLS, 2000, p. 107). Nesse 
sentido, o autor reforça que as redes são instrumentos apropriados pelo sistema capitalista face às necessidades de atender a economia globalizada, concentrada e ao mesmo tempo descentralizada, cuja morfologia se configura em relações de poder onde os conectores detêm esse poder.

Essas relações de poder são estabelecidas nos territórios pelos atores sociais que dispõe de poder político e econômico. Nesse sentido, as redes são feitas e desfeitas a partir de seus interesses num determinado território.

O território como a base do trabalho, o lugar da resistência, das trocas materiais e espirituais e do exercício da vida (SANTOS, 2006), onde são desenvolvidas as atividades socioeconômicas, ambientais e culturais.

Nesse viés, para compreender a complexidade da organização espacial, a partir da categoria de análise rede geográfica, essa pesquisa visa analisar a dinâmica produtiva considerando o potencial fitogeográfico para a produção de mel no Estado de Sergipe (Figura 01).

Figura 01: Divisão de Planejamento Territorial do Estado de Sergipe.

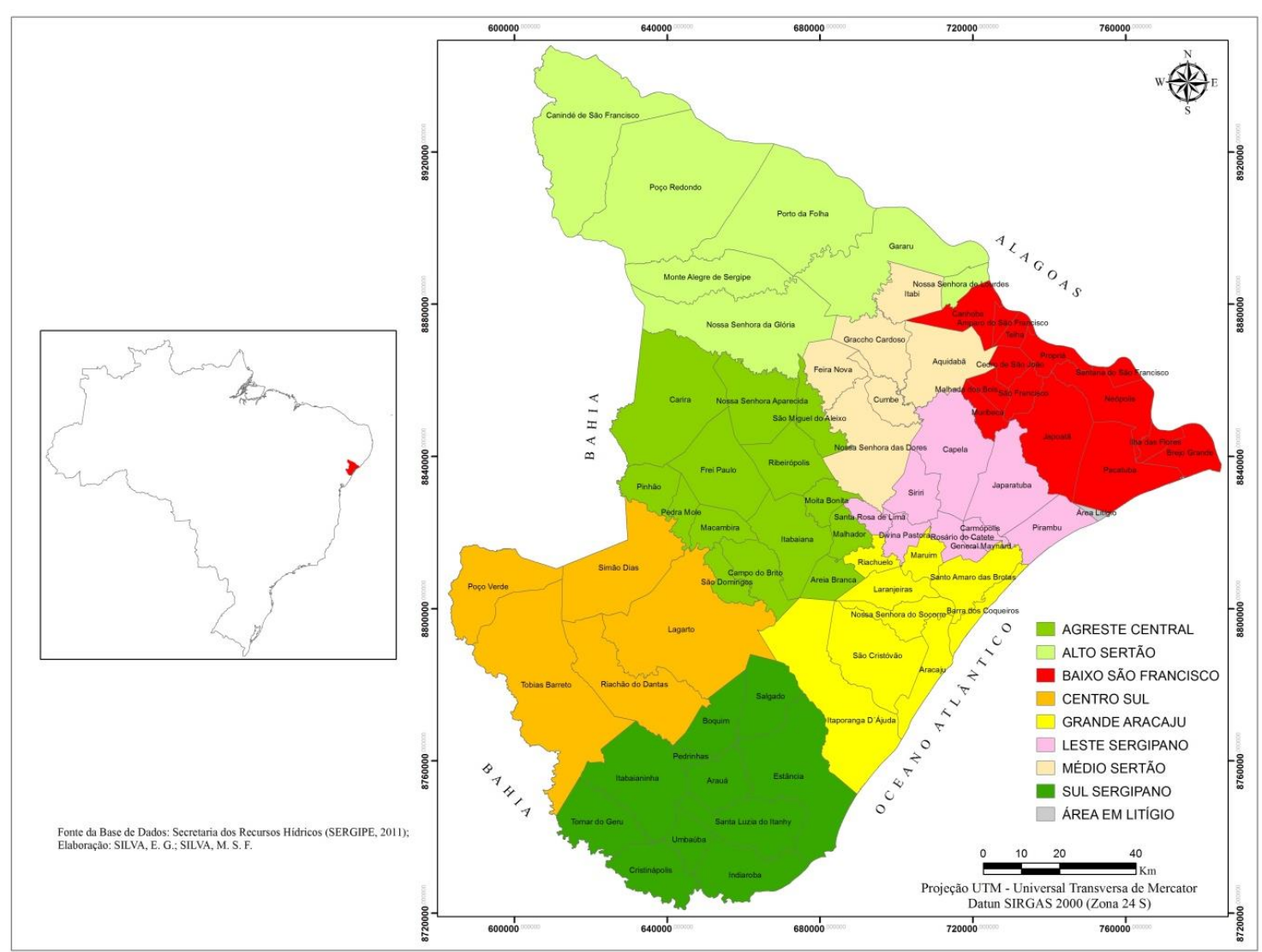

Fonte: SERGIPE, 2011. Elaboração: Silva e Silva, 2013. 
O potencial fitogeográfico está ligado ao uso dos territórios detentores de biodiversidade, tanto para atender as necessidades do presente como reservados para usos futuros. Todavia, esse potencial não envolve somente à proteção dos recursos naturais, pois abrange simultaneamente a defesa de interesses e das condições de vida dos atores sociais que dependem direta e/ou indiretamente da conservação de tais recursos (SILVA; MELO e SOUZA, 2009). Nesse trabalho esse potencial está vinculado à necessidade de conservação da biodiversidade para a produção apícola.

No tocante a dominação, apropriação e uso dos recursos naturais para a atividade apícola às redes estão ligadas à produção, ao controle e a comercialização, destacando: o potencial fitogeográfico dos territórios usados para apicultura; a comunicação entre os atores envolvidos na atividade ${ }^{4}$, em especial aqueles que participam e controlam a produção e o mercado nas mais variadas escalas geográficas; e, ao transporte.

Essa relação de poder está expressa no território, numa concepção materialista, que Santos (1994) define como extensão apropriada e usada. Por esse aspecto, o autor considera o território como a base do trabalho, o lugar da resistência, das trocas materiais e espirituais e do exercício da vida (SANTOS, 2006). Portanto, onde são desenvolvidas as atividades socioeconômicas, ambientais e culturais.

No âmbito da apicultura sergipana as redes geográficas são formadas basicamente pelas redes: de produção onde está incluído o potencial fitogeográfico usado para a atividade; técnica-científica, informacional e financeira que envolve o saber fazer, a pesquisa e os investimentos necessários o sucesso da atividade; e, a rede de comercialização responsável por distribuir os produtos no mercado nas mais variadas escalas geográficas.

Estruturalmente as redes têm como fator preponderante interligar os pontos e nós responsáveis pela produção, informação e comercialização de produtos. Sendo a apicultura uma atividade voltada para a produção, percebe-se a configuração de redes dispostas em âmbito local, nacional e mundial. A estrutura em rede facilita a informação, o escoamento da produção apícola e a comercialização, consequentemente fazendo chegar os produtos aos consumidores, ou seja, quanto mais densa for à rede, maiores serão os fluxos de informação, capital, conhecimento técnico e transportes, os quais têm grande relevância na análise da apicultura.

Quando se trata da esfera local, especialmente considerando os pequenos produtores de mel, essas redes encontram-se desarticuladas do ponto de vista produtivo, operacional,

\footnotetext{
${ }^{4}$ Apicultores, assistência técnica e financeira e atravessadores.
} 
técnico-científico, informacional, financeiro e da comercialização. Isso ocorre porque esses atores sociais encontram-se politicamente desarticulados e possuem poucos recursos financeiros dificultando a aquisição da base produtiva, ou seja, o potencial fitogeográfico para a produção de mel. Essa característica desencadeia uma série de problemas que enfraquecem a atividade devido a desarticulação dos nós das redes.

Nesse sentido, faz-se necessário criação e implementação de estratégias que visem estruturar as redes da apicultura conectando os principais nós na perspectiva de promover o acesso à base produtiva (potencial fitogeográfico disponível); a informação para capacitação e organização desses trabalhadores no setor produtivo, no beneficiamento e na comercialização; facilidades de créditos para estruturar a base produtiva e a estruturação e/ou implantação de unidades de beneficiamento (casa do mel); e, a criação ou implantação de cooperativas voltadas para atender as reais necessidades comerciais dos apicultores.

\section{PROCEDIMENTOS METODOLÓGICOS}

A pesquisa ocorreu mediante levantamento bibliográfico sobre a temática abordada; pesquisa de campo para identificação e análise dos territórios produtores de mel no Estado de Sergipe. Para aquisição das informações em Sergipe foram realizadas entrevistas ${ }^{5}$, a partir de roteiros semiestruturados, com os presidentes: da Federação dos Apicultores de Sergipe (FAPISE) e de cincos associações de apicultores federadas (Associação Sergipana de Apicultores - ASA, Associação de Apicultores do Município de Poço Verde - AAMPV, Associação de Apicultores do Treze - APISTREZE, Associação dos Pequenos Apicultores de Porto da Folha - APIFOLHA, e Associação de Melicultores do Alto Sertão- AMAS, além de entrevistas realizadas com 35 apicultores pertencentes a essas associações. Ademais, foram feitas visitas aos apiários na perspectiva de conhecer o potencial fitogeográfico ${ }^{6}$, as condições bioclimáticas e o acesso a esses ambientes.

Com o intuito de conhecer a estruturação e organização das associações de apicultores foi de fundamental importância participar de reuniões comumente realizadas por essas entidades com os apicultores associados. Após contatos e agendamentos prévios com os presidentes foi possível participar de cinco encontros na APISTREZE, em Lagarto e um

\footnotetext{
${ }^{5}$ As entrevistas e pesquisa de campo ocorreram entre março de 2010 e dezembro de 2012.

${ }^{6}$ Durante a pesquisa de campo foram identificadas as plantas melíferas a partir do nome vernacular indicado pelos apicultores.
}

Sociedade e Território - Natal. Vol. 28, N. 1, p. 70-87. Jan./Jun. de 2016 
encontro na ASA em Aracaju. No entanto, por motivos da distância e de agendamento não foi possível participar de reuniões nas demais associações pesquisadas.

Vale realçar que as entrevistas foram realizadas antes de iniciar as reuniões e após o seu término. Todavia, também ocorreram entrevistas durante as pesquisas de campo, as quais foram acompanhadas por apicultores. Na APISTREZE, cujas reuniões ocorreram no primeiro domingo de cada mês, entrevistou-se 20 apicultores e na ASA, onde as reuniões são realizadas nas terças-feiras de cada mês, foram entrevistados seis apicultores. No total, considerando-se as associações envolvidas na pesquisa, foram entrevistados 35 apicultores.

Os roteiros das entrevistas destinadas aos presidentes da federação, das associações de apicultores e da cooperativa de apicultores contemplaram questões visando conhecer a organização e a estruturação da atividade apícola, bem como os principais impasses e as perspectivas dessa atividade. Outra finalidade foi de conhecer as formas de comercialização e o destino do principal produto explorado, o mel.

As perguntas destinadas aos apicultores tratavam dos aspectos sociais, econômicos, produtivos (número de colmeias, forma de manejo e produtividade/colmeia) e ambientais, destacando, a qualidade do pasto apícola, as principais espécies vegetais visitadas pelas abelhas, os períodos das floradas, dentre outras.

As informações coletadas foram usadas para realizar mapeamento das redes geográficas da apicultura sergipana bem como da área de influência do Município de Ribeira do Pombal-BA em Sergipe uma vez que as redes ultrapassam os limites territoriais de Sergipe. Os mapas foram confeccionados a partir do uso do software ArcGis 9.3.

Essas informações oportunizaram compreender a organização, a estruturação da atividade apícola, os principais impasses e as perspectivas dessa atividade, bem como a situação dos apicultores no que concerne aos aspectos sociais, econômicos, produtivos, ambientais e da apropriação e uso dos recursos naturais que permeiam a rede da apicultura local.

\section{RESULTADOS E DISCUSSÃO}

A análise da apicultura através da categoria rede geográfica possibilita a compreensão da (des)estruturação da atividade sendo possível compreender a configuração geográfica na perspectiva de apontar caminhos que possam contribuir para a conexão dos nós e o fortalecimento da apicultura na esfera local. 
A organização espacial a partir das redes geográficas visando entender a dinâmica territorial da apicultura envolve simultaneamente: os territórios com potencial fitogeográfico; os meios de produção, ou seja, os instrumentos, equipamentos e instalações usadas na produção e no beneficiamento dos produtos da colmeia ${ }^{7}$; o meio técnico-científico, informacional e financeiro; e a comercialização. Assim, são vários os atores sociais com interesses diversos envolvidos na atividade apícola, desde a produção até a comercialização. Nesse jogo de interesses destacam-se as forças antagônicas com poder políticos e econômicos que agem para dominar aqueles que não possuem poder de barganha, especialmente os apicultores.

É nesse viés que as redes geográficas da apicultura sergipana se constituem como instrumento de articulação e/ou desarticulação, onde são mantidas relações de poder, cuja (des)estruturação gera perdas substanciais para os pequenos produtores locais, principalmente na comercialização em função dos baixos preços estipulados pelos entrepostos, especialmente para o mel de abelha.

Nessa direção, a rede envolve simultaneamente o sistema produtivo, abrangendo os territórios que dispõem de potencial fitogeográfico; os apicultores enquanto atores sociais detentores do conhecimento para produzir; a confederação, as federações e as associações de apicultores enquanto entidades organizacionais do sistema produtivo; e as entidades que prestam apoio técnico-científico e financeiro. Já a rede de comercialização é composta pelos atores que facilitam e/ou estão diretamente ligados a compra e venda dos produtos apícolas.

Essas redes também agem em locais onde já existia a atividade, embora de forma embrionárias, como é o caso de Sergipe. Nesse aspecto, as redes agem para fortalecer e ampliar a produção local via melhoramento do manejo da atividade, facilitando o transporte e comercialização dos produtos.

\section{A (des)conectividade das redes geográficas da apicultura sergipana}

Em Sergipe, assim como outros Estados da Região Nordeste ${ }^{8}$, os territórios com potencial fitogeográfico usados para a produção apícola face as condições naturais,

\footnotetext{
${ }^{7} \mathrm{Mel}$, cera, pólen, própolis, apitoxina (veneno da abelha) e geléia real.

${ }^{8}$ A exemplo de Limoeiro do Norte no Ceará, maior produtor de mel do país; Araripina-PE, segundo maior produtor; Apodi-RN, terceiro maior produtor, e, Picos-PI, o sexto maior produtor (BRASIL, 2009) os quais produzem mel usando o potencial fitogeográfico da vegetação de caatinga, o que fortalece a acepção da aptidão natural desse bioma para a produção de mel.
} 
especialmente a partir do uso das espécies florísticas da vegetação da Caatinga, propícias para a produção de mel. Esses produtos, principalmente o mel vêm sendo bastante procurado pelo mercado consumidor da Europa, por apresentar características peculiares ao mel orgânico. Por outro, lado à estruturação da rede nem sempre beneficia todos os atores na mesma proporção.

Nesse Estado a configuração inicial da rede geográfica da apicultura está calcada no uso dos territórios com potencial fitogeográfico para produção, embora os apicultores nem sempre possuam a propriedade da terra. A rede de produção ultrapassa as fronteiras de Sergipe rumo aos municípios do sertão da Bahia.

Essa (des)configuração está atrelada à inexistência de alguns componentes importantes para eficácia do arranjo, como: centro de pesquisa voltado para atividade apícola; entreposto para comercialização dos produtos explorados; e falta de casa do mel obedecendo as normas da vigilância sanitária na maior parte dos territórios pesquisados, com exceção da casa do mel de Poço Verde (Figura 02) a qual foi construída dentro dos padrões recomendados. Este último elemento é um dos maiores entraves para apicultura sergipana, pois sem um local propício, dentro das normas vigentes para o beneficiamento dos produtos apícolas, o produtor não consegue a certificação, considerada fundamental para a comercialização.

Figura 02: Casa do Mel de Poço Verde-SE.

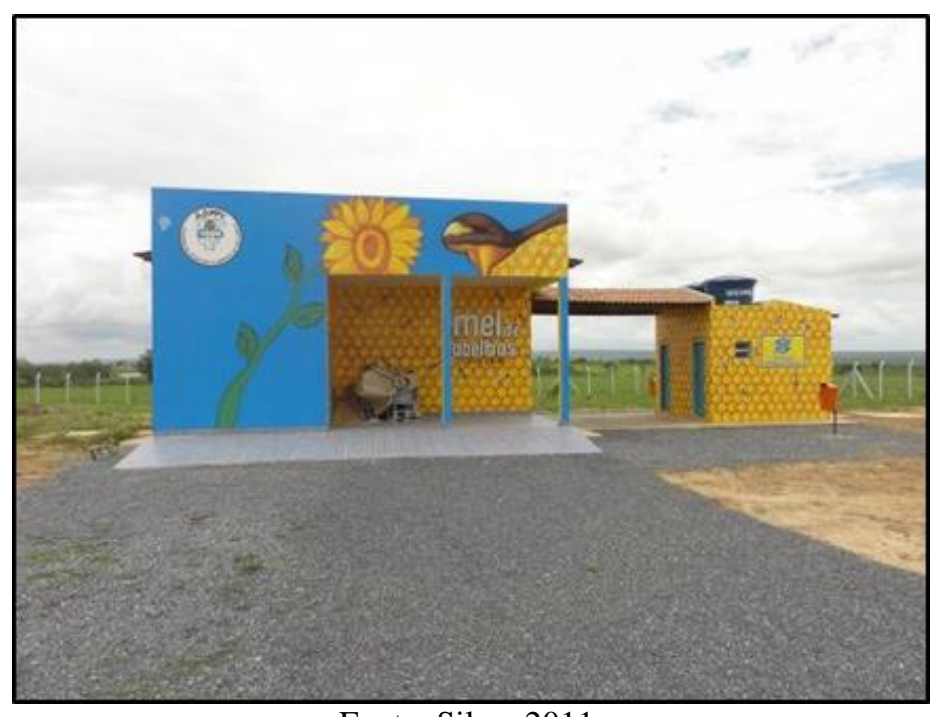

Fonte: Silva, 2011.

A configuração das redes geográficas em Sergipe (Figura 3) da apicultura é formada pelas redes de produção a partir dos territórios detentores de potencial fitogeográfico; técnicacientífica e informacional; em redes de comercialização. 
A rede de produção ultrapassa as fronteiras do Estado de Sergipe rumo aos municípios do sertão da Bahia cujas potencialidades florestais são aproveitadas pelos apicultores sergipanos que migram suas colmeias, principalmente da Colônia Treze, em Lagarto, que vem comprando propriedades nesse Estado e/ou realizando parcerias com os donos das terras para aumentar sua produção (Figura 03).

Figura 03: Redes Geográficas da Apicultura Sergipana em 2012.

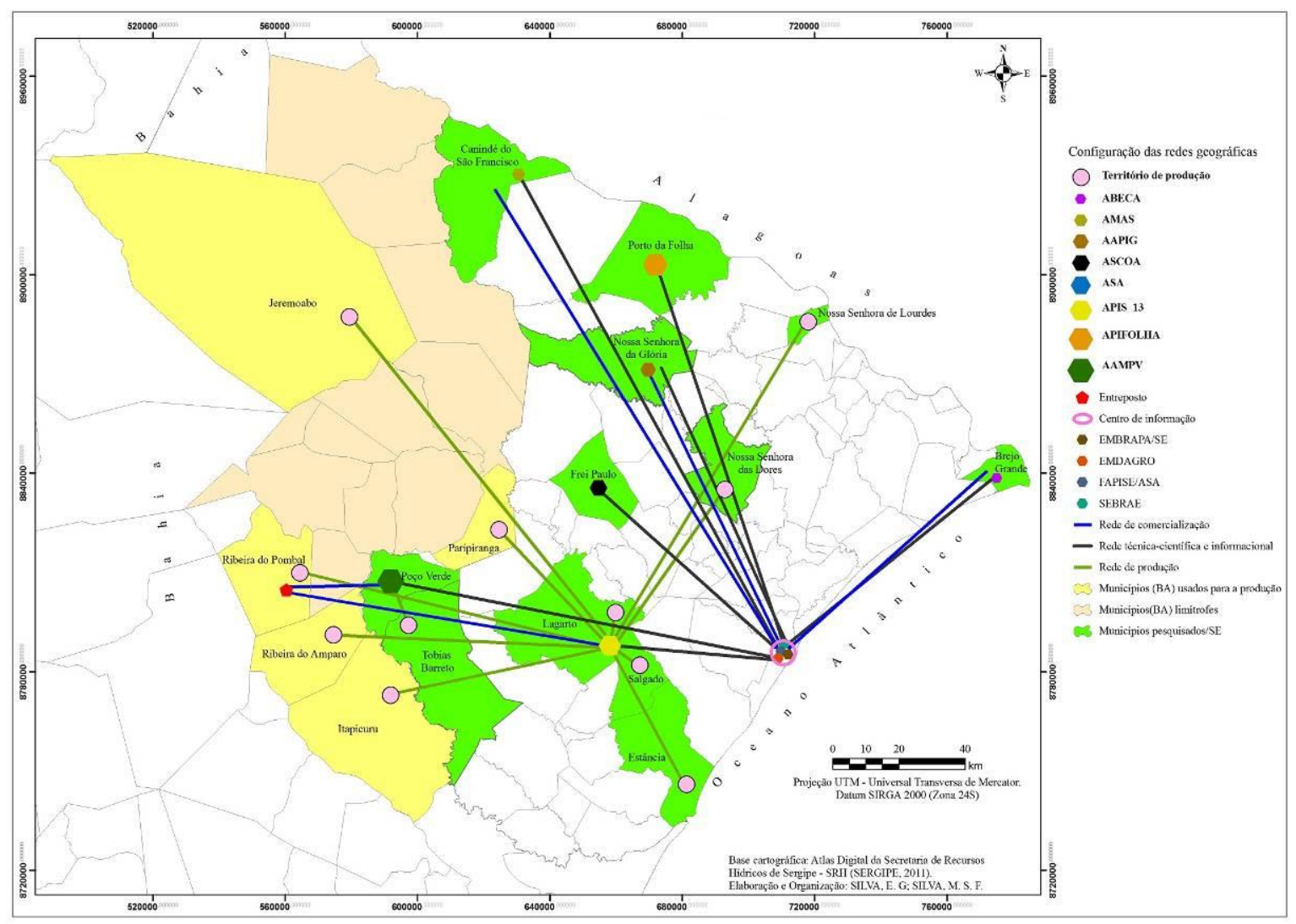

Fonte: Pesquisa de Campo, 2011 - 2013. Elaboração: Silva e Silva, 2013.

Dentre os principais entraves que fragilizam a rede de produção destacam-se:

a) Propriedade de terras: uma vez que parcela dos apicultores não dispõe de propriedades particulares para fixação dos apiários, o que os leva em busca de outras alternativas para produzir, como por exemplo, arrendamento ou parceria com os proprietários. Esse entrave apresenta várias desvantagens, tais como: a redução dos lucros devido ao acordo com os proprietários que visam à partilha e/ou pagamentos; a retirada de colméias, uma vez que há casos que os proprietários desfazem das parcerias sem respeitar o período das floradas, para dar outras finalidades a terras, mesmo que as colméias ocupem pouco espaço, rompendo 
assim, o ciclo de produção e, consequentemente, causando prejuízos tanto financeiro como naturais através da perda de enxames.

b) Proximidade de apiários em locais com uso intensivo de agrotóxicos: isso ocorre em regiões com predomínio de cultivos, como em Lagarto, no caso do uso de agrotóxico principalmente nas laranjeiras e no Município de Poço Verde cujo uso intensivo nas plantações de milho, tem provocado à mortandade das abelhas.

c) Manejo do apiário: neste entrave considera-se que o conhecimento deficiente por parcela dos apicultores reduz a produtividade por colméia, como: a falta de renovação da rainha ${ }^{9}$; o adensamento de colméias em uma determinada área resultando na concorrência entre as abelhas que passam a disputar alimentos; dimensões inadequadas nas caixas, aumentado o trabalho das abelhas para produção de cera; e, deficiência de monitoramento e controle da produção por colméia.

d) Recursos financeiros: apesar da apicultura ser uma atividade econômica, considerada por grande parte das literaturas que requer baixo investimento inicial, observouse nas áreas de estudo que os recursos financeiros estão entre os principais fatores que impedem o crescimento. Para um iniciante que pretenda investir na atividade é preciso, além do pasto apícola, de equipamentos usados diretamente na produção, como caixas (Figura 04), vestimenta e fulmegador.

Figura 04: Colmeia padrão langstroth.

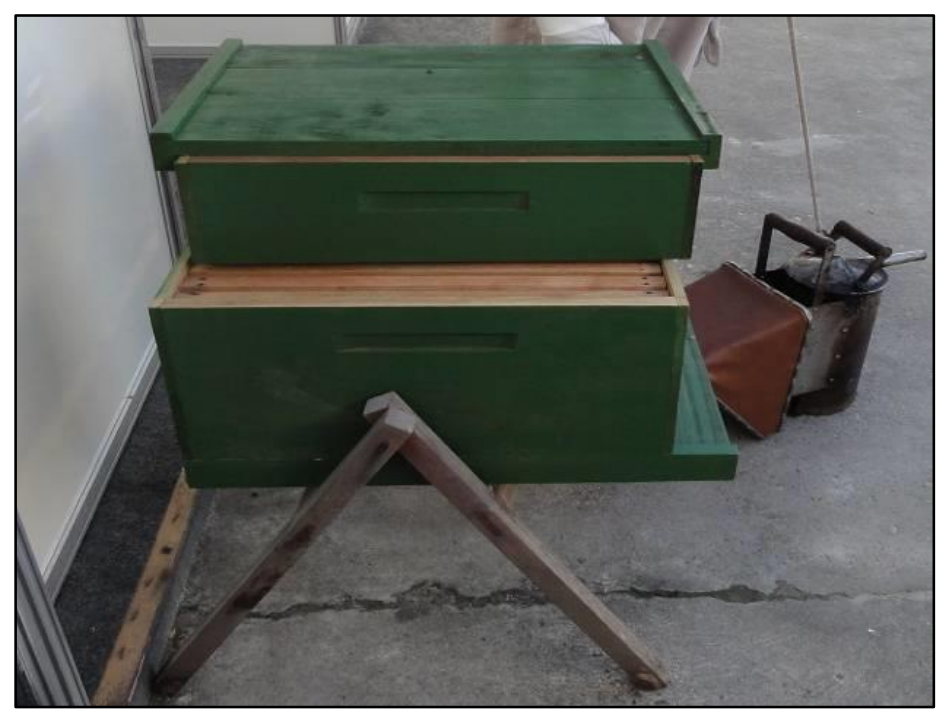

Fonte: Silva, 2011.

\footnotetext{
${ }^{9}$ A rainha é responsável pela reprodução das abelhas operárias. Com o tempo diminui a fecundidade da rainha, reduzindo a população do enxame, havendo necessidade de substituição por uma nova rainha.
} 
Um kit de colméia ${ }^{10}$ (Figura 05) custa cerca de dois mil reais, o que mostra que o investimento não é tão baixo considerando-se a situação socioeconômica dos produtores do sertão compara com outras atividades;

Figura 05: Kit de proteção do apicultor: Macacão com mascara, luvas, botas, e o fulmegador.

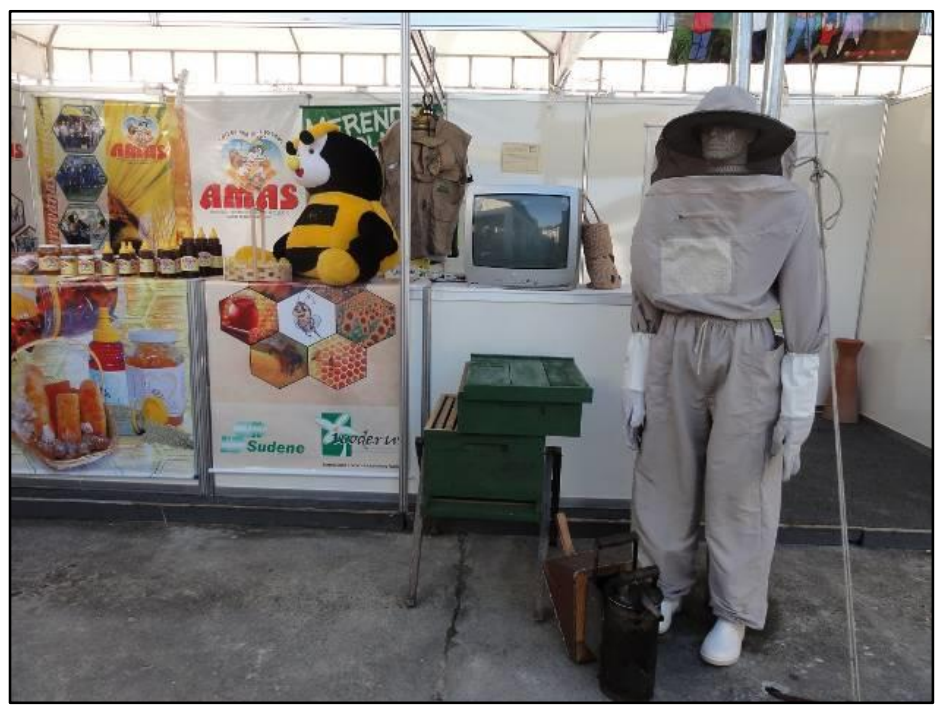

Fonte: Silva, 2011.

e) Fatores naturais: as condições climáticas interferem diretamente no pasto apícola.

No caso do sertão, um ano com condições atípicas pode comprometer sensivelmente a produção anual, como o que ocorreu em 2011, cujos produtores tiveram redução drástica da produção de mel. A proximidade de água é fundamental, pelo menos num raio de $1,5 \mathrm{~km}$ do apiário o qual é considerado o raio de ação das abelhas ${ }^{11}$, o que carece de atenção especial por parte dos apicultores do sertão sergipano que usam como estratégia usar recipientes com água nas proximidades dos apiários quando não dispõem de fonte natural.

f) Unidade de extração e processamento apícola - Casa do Mel: é um dos entraves que mais dificultam a produção, pois nesse estabelecimento há equipamentos de suma importância para o beneficiamento do mel obedecendo às normas da vigilância sanitária estadual e federal. Esse é um dos requisitos que tem dificultado as associações de apicultores sergipanas, tendo em vista que para obtenção de uma estrutura adequada requer um investimento elevado inviável quando não se tem apoio governamental e/ou de fundações.

\footnotetext{
${ }^{10}$ Contém dez caixas com ninho e uma melgueira, vestimenta completa e fulmegador.

${ }^{11}$ Costa; Oliveira (2005).
} 
Embora os entraves sejam os mais variados essa atividade encontra-se em plena expansão, principalmente a partir de 2003, com o lançamento do Projeto QQC ${ }^{12}$ do mel tendo como meta fortalecer o setor através de investimentos na organização e capacitação dos apicultores, no desenvolvimento de mercados e na conservação ambiental (SERGIPE, 2008).

A rede técnica-científica e informacional é composta pelas entidades: SEBRAE, EMDAGRO e FAPISE as quais prestam apoio aos apicultores através de cursos de capacitação e manejo do apiário e visitas técnicas quando solicitadas pelas associações de apicultores. A presença desses órgãos estimulou o inicio da atividade apícola em vários municípios, como em Canindé de São Francisco, cuja prática surge a partir da chegada do SEBRAE a região em 2005.

A rede financeira está composta pelo Banco do Brasil que atua praticamente em todo Estado via empréstimos concedidos aos apicultores; pela Companhia de Desenvolvimento do Vale do São Francisco (CODEVASF), com projetos em Canindé de São Francisco e Porto da Folha, pelo Banco Nacional do Desenvolvimento (BNDS) via financiamento não reembolsáveis (fundos perdidos), cujos projetos tendem fortalecer a atividade apícola.

$\mathrm{Na}$ análise das redes deve-se considerar que os empréstimos concedidos por instituições financeiras muitas vezes aprisionam tanto o apicultor que fez o empréstimo como o avalista, geralmente outro apicultor. Sendo assim, se um se tornar inadimplente, automaticamente o outro se torna, ficando assim, impossibilitados de realizar novos empréstimos.

Há ainda casos que as associações de apicultores tornam-se avalistas de seus associados, ficando a mercê dos bancos para sanar as dívidas dos apicultores. Nesses casos há exemplos de associações que acabam perdendo seus equipamentos e bens imóveis que foram colocados a leilões pelos próprios bancos para sanar tais dívidas. Quando essas dívidas são de vários apicultores, tornando-se impagáveis pelas associações que não dispõem de capital para quitação das dívidas, encontram como alternativa fechar a associação com perspectiva de abertura de uma nova instituição com outra razão social, pois a anterior perdeu os privilégios de se quer submeter projetos e realizar novas transações financeiras com qualquer outra entidade.

Essas análises corroboram com Raffestin (1993) quando realça que as redes podem promover a liberdade e ao mesmo tempo aprisiona os atores sociais. Sendo assim, a rede financeira tanto liberta os atores sociais que lidam com apicultura, quando concede os

\footnotetext{
${ }^{12}$ Qualidade, Quantidade e Continuidade.
} 
empréstimos, como os aprisiona na medida em que não conseguem sanar suas dívidas. Essas redes são feitas e desfeitas a partir dos interesses daqueles atores que dispõe do poder, seja ele político ou econômico.

A rede de comercialização de Sergipe basicamente é formada pela COOAPISE, e pelo entreposto localizado em Ribeira do Pombal, na Bahia, onde este tem grande influência em partes dos municípios de Sergipe que desenvolve a apicultura (Figura 6). Quando a comercialização é feita através da Cooperativa os apicultores conseguem um preço mais justo, entorno de $\mathrm{R} \$ 6,00$ o quilo. Em contrapartida quando vendem diretamente ao entreposto o preço varia entre $\mathrm{R} \$ 3,40$ e $\mathrm{R} \$ 3,80$ a depender do tipo de mel.

Vale frisar que os apicultores optam pela venda diretamente ao entreposto por vários motivos, tais como: a venda demorada de porta em porta, distância da sede da Cooperativa a qual é dificultada pelos custos do transporte, deficiência de recursos financeiros, dentre outros.

Uma das formas mais rentável de comercializar o mel ocorre quando há convênio entre as associações de apicultores e o governo estadual e municipal, através de projetos da Companhia Nacional de Abastecimento (CONAB) que visa melhorar a qualidade da merenda escolar, inserindo vários produtos naturais, inclusive o mel.

A falta de certificação do mel através do Selo de Inspeção Estadual (SIE) e do Selo de Inspeção Federal (SIF) é um dos principais entraves para a comercialização. Essa ausência acaba repercutindo diretamente nos pequenos apicultores que se veem obrigados a entregar seus produtos aos preços estipulados pelos atores sociais que dominam o mercado.

As análises demonstram que a rede de comercialização sergipana, influenciada pelo entreposto localizado no Estado da Bahia, tem gerado de certa forma um aprisionamento dos produtores, que devido aos entraves apresentados não encontram outras alternativas de venda, o que os faz optar por entregar a produção a este entreposto por um preço inferior a venda a varejo.

Nessa relação com o território às redes de produção, técnica, científica e informacional, financeira e, principalmente a rede de comercialização, efetivamente possui uma relação ambígua, ora como fator de coesão quando articulam os apicultores para melhor produzir para o mercado. Ora funcionam como desarticuladoras na medida em que os apicultores não conseguem pagar os empréstimos concebidos pelas entidades financeiras não tendo possibilidades de almejar o crescimento da produção. 
No âmbito da rede de produção e da técnica, científica e informacional a FAPISE vem realizando um trabalho visando o fortalecimento dessas redes. Contudo, ainda não é percebida que essa federação ainda não consegue conectar todos os nós (associações de produtores) dessas redes, o que gera fragilidade especialmente para os pequenos produtores que dependem desses canais para manter e/ou aumentar sua produção a partir da sustentabilidade ambiental.

Os atores sociais que dominam as redes de comercialização, consequentemente o mercado, têm papel fundamental na desarticulação dos apicultores, pois comumente se submetem a venderem seus produtos aos atravessadores a preços aquém do que é praticado no mercado nacional e internacional.

\section{Figura 06: Área de Influência de Ribeira do Pombal (BA) em Sergipe}

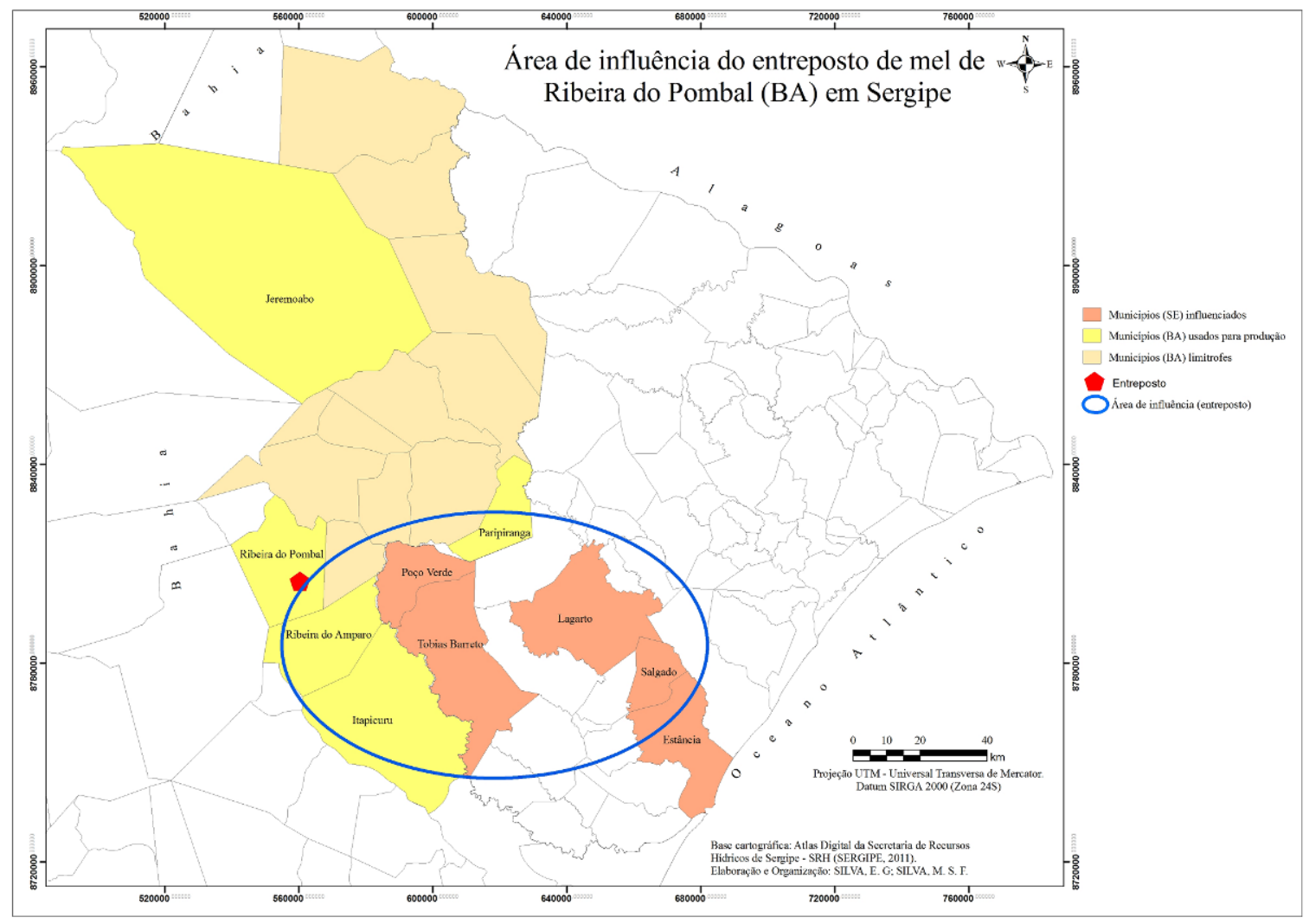

Fonte: Pesquisa de Campo 2011 - 2013. Elaboração: Silva e Silva, 2013.

Vale ressaltar que a COAPISE poderia ser a principal receptora e, consequentemente fortalecer os canais de comercialização do mel produzido em Sergipe. Entretanto, os interesses antagônicos existentes dificultam o relacionamento entre os produtores e essa cooperativa, demonstrando o enfraquecimento do capital social nesta atividade. 
Essas fragilidades poderiam ser contornadas a partir de medidas apoiadas nos preceitos da do capital social e da governança na perspectiva ampliar os relacionamentos sociais entre os atores envolvidos melhorando a gestão da atividade apícola e, efetivamente contribuir para reduzir os custos operacionais que envolvem a produção e beneficiamento do mel.

\section{CONCLUSÃO}

As redes geográficas da apicultura são representadas pelas redes de produção, de assistência técnica-científica, informacional e financeira, e, de comercialização. A primeira envolve a base produtiva e de beneficiamento, ou seja, os territórios com potencial fitogeográfico, as unidades de beneficiamento (casa do mel) e o setor organizacional (associações e federações). Essas redes encontram-se em fase de estruturação, pois a apicultura em Sergipe é recente. Nesse sentido é perceptível há carência de instalações e equipamentos apropriados, informações técnicas-científicas, auxílio financeiro, além da desarticulação na comercialização.

Dentre os entraves que permeiam a rede de produção destacam-se: a dificuldade de acesso a terra com potencial produtivo por parcela dos apicultores tornando-os vulneráveis a constantes problemas, como por exemplo, a remoção das caixas quando os proprietários, por algum motivo, exigem a retirada sem esperar o período de colheita do mel, causando grandes prejuízos aos produtores; condições naturais, principalmente no sertão nordestino onde os apicultores podem enfrentar longos períodos de estiagem; uso intensivo de agrotóxicos no entorno das áreas produtivas, provocando a mortandade das abelhas; unidades de beneficiamento não adequadas às normas sanitárias, ou até mesmo a inexistência dessas estruturas próximas a locais de produção; desarticulação nas associações de apicultores.

A rede de assistência técnica-científica, informacional e financeira é formada especialmente pela: a Confederação Brasileira de Apicultores; federações de apicultores; órgãos públicos de apoio técnico-científico e financeiro; e entidades financeiras. Dentre os desafios encontrados para a (re)estruturação dessa rede pode-se citar as dificuldades de acesso a créditos visando o financiamento da produção apícola.

Na rede de comercialização os elementos essenciais são: Cooperativas de apicultores de Sergipe e os entrepostos. Os principais gargalos que impedem o sucesso da apicultura estão vinculados à dificuldade de obtenção dos selos de inspeção sanitária, como o Selo de 
Inspeção Federal (SIF); a monopolização do setor pelos entrepostos e atravessadores; e, a desorganização e desarticulação do ponto de vista funcional da cooperativa.

Para contornar as dificuldades presentes na rede de produção é de suma importância criar e implementar alternativas que possibilitem o acesso a terra, como áreas comunais que possam ser usadas por aqueles apicultores que enfrentam tais dificuldades. Ademais, outras opções que podem ser usadas pelos apicultores são as terras da União e os Espaços Territoriais Legalmente Protegidos (ETPs), dentre elas as Unidades de Conservação e as Áreas de Preservação Permanentes (APPs) localizadas distantes de espaços densamente ocupados.

Outra estratégia pertinente está ligada a realização de convênios e/ou parcerias via órgãos oficiais com proprietários de terras, cujos territórios que têm potencial fitogeográfico possam ser disponibilizados para o uso da atividade apícola. Outrossim, é fundamental campanhas educativas com os proprietários e funcionários das propriedades para evitar desmatamento e o uso intensivo de agrotóxicos em áreas que apresentam potencial para a apicultura.

As palestras e demais estratégias que objetivam melhorar o funcionamento da rede de assistência, técnica-científica e financeira também são prioritárias para os apicultores para melhorar o manejo e aprimorar seus conhecimentos "saber fazer" para aumentar a produção de mel e demais produtos da colmeia. Vale frisar a necessidade de criação e implementação de Centros de Tecnologia voltados para a apicultura, a exemplo do Centro de Tecnologia Apícola situado em Picos-PI, com o objetivo de melhorar a qualidade do mel e seus derivados.

Para os apicultores é crucial que os órgãos de apoio técnico-científico e informacional ajudem na articulação política organizando as associações e cooperativas. Ademais, é preciso fornecer apoio financeiro, via empréstimos concedidos pelas entidades, com facilidades para a quitação das dívidas dos apicultores. Igualmente, é preciso elaborar e implementar políticas públicas que facilitem a aquisição de propriedade de terra e equipamentos necessários para manter e/ou aumentar a produção de mel.

É relevante que esses trabalhadores recebam apoio de entidades técnicas para elaboração e submissão de projetos para aquisição de fomentos que contribuam para (re)estruturar a atividade do ponto de vista operacional, facilitando a aquisição de equipamentos necessários para manter e/ou aumentar a produção de mel e infraestrutura básica, como a casa do mel e pontos de apoio, principalmente para aqueles apicultores cujos 
pastos apícolas estão distantes da casa do mel. Essa estratégia pode ajudar conectar os nós que articulam a rede de produção e a de comercialização.

Com o intuito de amenizar os empecilhos existentes na rede de comercialização os pequenos produtores podem organizar as redes locais a partir da criação e/ou fortalecimento das associações e cooperativas visando melhorar a produção e a comercialização de maneira que não dependam exclusivamente do atravessador para a comercialização dos produtos. Essas estratégias são fundamentais para a permanência dos apicultores no setor produtivo, consequentemente ocasionando o fortalecimento das redes em escala local.

Nesses parâmetros o estudo das redes geográficas pode contribuir para compreensão da (des)estruturação da apicultura, cujas análises podem indicar caminhos para melhorar seu funcionamento, aprimorando a articulação entre os componentes dessa atividade, tais como: os produtores, as entidades que promovem assistência técnica-científica e informacional e as responsáveis pela comercialização do produto no mercado local, nacional e global.

Ademais, há perspectiva de investimentos financeiros para aumentar a produção de mel face ao potencial fitogeográfico, como no semi-árido. As evidências apontam que a produção de mel em Sergipe poderá crescer nos próximos anos. Contudo, faz-se necessário desenvolver pesquisas voltadas para a investigação das potencialidades fitogeográficas tanto nas localidades onde a apicultura vem se consolidando, a exemplo do sertão sergipano, como em outros territórios que ainda apresentam baixa capacidade de produção. Assim, é preciso criar estratégias que contemplem a conservação socioeconômica e ambiental, atreladas ao fortalecimento da atividade.

Do ponto de vista ecológico, para que uma rede da apicultura se torne sustentável é necessário ter pasto apícola; práticas de manejo adequadas visando conservar a biodiversidade almejando a produção orgânica; campanhas educativas para minimizar o desmatamento, as queimadas e os impactos ambientais; investimentos no setor produtivo; e a criação de áreas comunais para a produção.

É fundamental ressaltar a importância da apicultura para Sergipe e para os demais Estados da federação que têm potencial fitogeográfico para seu desenvolvimento. Pois de um lado é fonte alternativa de renda para milhares de apicultores, melhorando sua qualidade de vida. E do outro, ajuda na conservação ambiental dos recursos naturais através da polinização, contribuindo para perpetuação das espécies vegetais, melhorando a produtividade dos cultivos agrícolas. Além do mais, esse potencial é responsável pela manutenção dos demais atributos biofísicos. 


\section{REFERÊNCIAS}

COSTA, P. S. C.; OLIVEIRA, J. S. Manual prático de criação de abelhas. Viçosa: Aprenda Fácil, 2005. 405 p.

BRASIL. Produção da Pecuária Municipal 2009. v. 37. Rio de Janeiro, IBGE, 2009.

CASTELlS, M. A. Sociedade em Rede - A Era da Informação: Economia, Sociedade e Cultura. v. 1. São Paulo: Paz e Terra, 2000. (Tradução de Roneide Venâncio Majer com colaboração de Klauss Brandini Gerhardt).

CORRÊA, R. L. Redes Geográficas: cinco pontos para discussão. In: Vasconcelos, P. A. S.; Silva, S. B. M. Novos estudos de geografia urbana brasileira. Salvador: UFBA, 1999.

COSTA, P. S. C.; OLIVEIRA, J. S. Manual prático de criação de abelhas. Viçosa: Aprenda Fácil, 2005. 405 p.

MOREIRA, R. Da região à rede e ao lugar: a nova realidade e o novo olhar geográfico sobre o mundo. ETC...., espaço, tempo e crítica. 2007. n. 13, v. 1, 1 de jun. p. 55-70.

RAFFESTIN, C. Por uma geografia do poder. São Paulo: Ática, 1993.

SANTOS, M. O dinheiro e o território. In: Santos, M. et al. Território e territórios: ensaios sobre o ordenamento territorial. Rio de Janeiro: DP\&A, 2006. p. 13-21.

SANTOS, M. O retorno do território. In: SANTOS, M.; SOUZA, M. A. A.; SILVEIRA, M. (Orgs.). Território, globalização e fragmentação. São Paulo: Hucitec/ANPUR, 1994. p. 1520.

SERGIPE. Plano de desenvolvimento preliminar do arranjo produtivo de apicultura sergipana. SEDECT, 2008.

SILVA, M. S. F.; SOUZA, R. M. O potencial fitogeográfico de Sergipe: uma abordagem a partir das unidades de conservação de uso sustentável. Scientia Plena. Aracaju, 2009. v. 5, n. 10. p. $1-10$.

\section{Recebido em Outubro de 2014}

Aprovado em Março de 2016

Publicado em Junho de 2016 